\title{
Cellular Energy Absorbing TRIP-Steel/Mg-PSZ Composite: Honeycomb Structures Fabricated by a New Extrusion Powder Technology
}

\author{
Ulrich Martin, ${ }^{1}$ David Ehinger, ${ }^{1,2}$ Lutz Krüger, ${ }^{2}$ Stefan Martin, ${ }^{1}$ Thomas Mottitschka, ${ }^{2}$ \\ Christian Weigelt, ${ }^{3}$ Christos G. Aneziris, ${ }^{3}$ and Mathias Herrmann ${ }^{4}$ \\ ${ }^{1}$ Institute for Materials Science, Freiberg University of Mining and Technology, Gustav-Zeuner Straße 5, 09596 Freiberg, Germany \\ ${ }^{2}$ Institute for Materials Engineering, Freiberg University of Mining and Technology, Gustav-Zeuner Straße 5, 09596 Freiberg, Germany \\ ${ }^{3}$ Institute for Ceramics, Glass and Construction Materials, Agricolastraße 17, Freiberg University of Mining and Technology, \\ 09596 Freiberg, Germany \\ ${ }^{4}$ Fraunhofer Institute for Ceramic Technologies and Systems, Winterbergstraße 28, 01277 Dresden, Germany
}

Correspondence should be addressed to Ulrich Martin, martin@ww.tu-freiberg.de

Received 26 March 2010; Revised 20 July 2010; Accepted 30 September 2010

Academic Editor: John W. Gillespie

Copyright ( 2010 Ulrich Martin et al. This is an open access article distributed under the Creative Commons Attribution License, which permits unrestricted use, distribution, and reproduction in any medium, provided the original work is properly cited.

Lightweight linear cellular composite materials on basis of austenite stainless TRIP- (TRansformation Induced Plasticity-) steel as matrix with reinforcements of $\mathrm{MgO}$ partially stabilized zirconia (Mg-PSZ) are described. Two-dimensional cellular materials for structural applications are conventionally produced by sheet expansion or corrugation processes. The presented composites are fabricated by a modified ceramic extrusion powder technology. Characterization of the microstructure in as-received and deformed conditions was carried out by optical and scanning electron microscopy. Magnetic balance measurements and electron backscatter diffraction (EBSD) were used to identify the deformation-induced martensite evolution in the cell wall material. The honeycomb composite samples exhibit an increased strain hardening up to a certain engineering compressive strain and an extraordinary high specific energy absorption per unit mass and unit volume, respectively. Based on improved property-to-weight ratio such linear cellular structures will be of interest as crash absorbers or stiffened core materials for aerospace, railway, or automotive applications.

\section{Introduction}

In the last two decades the manufacturing and use of composite materials and cellular designs, which acquired their crashworthiness by pursuing a novel concept, mostly based on an artificial replica of the nature's light weight constructions, have gained enormous importance [1-5].

Porous materials, such as metal foams, hollow sphere agglomerates, or honeycomb structures, are well known for their excellent stiffness-to-weight ratio and high energy absorption according to their three-dimensional or twodimensional cell topologies. The wide variety of mechanical and physical properties makes them useful in sandwich panels, impact energy absorption, or acoustical wave attenuation [6]. Rabiei et al. $[7,8]$ have generated a new type of crash- absorbing foam based on steel hollow spheres in random dense arrangement whose interstitial spaces are closed by filling with stainless steel powder and final sintering. During quasistatic compression this stainless steel foam achieved an average plateau stress of $136 \mathrm{MPa}$ and a specific energy absorption of $68 \mathrm{MJ} \mathrm{m}^{-3}$ at $50 \%$ strain. Closed cell steel foams, synthesized by mixing and compacting Fe-2.5C powder with $\mathrm{MgCO}_{3}$ or $\mathrm{SrCO}_{3}$ as foaming agents and final heating for gas expansion, were presented by Park and Nutt [9]. The material with a density of $3.4 \mathrm{~g} \mathrm{~cm}^{-3}$ showed a specific energy absorption of about $44 \mathrm{MJ} \mathrm{m}^{-3}$ at the same strain level.

Metallic honeycomb structures are conventionally fabricated in two different ways; either thin sheets of metal or polymers are bent to flexible profiles which are finally strip 
bonded and expanded or corrugated, stacked, and welded to an assembly [10-12]. Stainless steel squarehoneycombs manufactured by strip slotting process are introduced by Côté et al. [13] and Radford et al. [14], respectively. Baker et al. [15] studied the material behavior of corrugated 304 stainless steel honeycomb structures with a global density of $2.9 \mathrm{~g} \mathrm{~cm}^{-3}$ and a sheet thickness of $381 \mu \mathrm{m}$ under quasistatic and dynamic compression. Specific energy absorption of 70 and $90 \mathrm{MJ} \mathrm{m}^{-3}$ at $40 \%$ strain could be observed [15]. However, the stamping or crimping process is generally limited to only uniform hexagonal hollow structures.

Integrating fine dispersed ceramic particles into the ductile metal matrix, failure-tolerant and wear-resistant metal matrix composites (MMCs) can be generated. With the combination of Y-PSZ and high-alloyed TRIP-steel as matrix by hot pressing, Guo et al. [16, 17] achieved compressive strengths of about 1400 up to $2100 \mathrm{MPa}$ with respect to dynamic high-rate deformation.

In a previous research, Aneziris et al. [18] modified a conventional ceramic extrusion technology to create filigree honeycomb designs based on Mg-PSZ-reinforced austenite TRIP-steel matrix composites. With the application of this technology, novel two-dimensional cellular composites are realized, revealing superior energy absorption, corrosion, and wear resistance. The presented material can be assigned to a unique class of material concentrating on metastable austenite TRIP-steel with Mg-PSZ, the so-called TRIPmatrix composites (TRIP-MCs).

Biermann et al. [19] used the conventional cold isostatic pressing (CIP) route in order to manufacture compact rods of the same precursor compositions. The particle-reinforced TRIP-steel/zirconia composites exhibited higher compression and bending strengths compared to the zirconia-free reference samples. Furthermore, the extruded honeycomb composite materials were studied with respect to energy absorption behavior and microstructure evolution during out-of-plane (perpendicular to the cell plane) compressive deformation. The highest energy absorption achieved by an unreinforced TRIP-steel honeycomb prototype was $143 \mathrm{MJ} \mathrm{m}^{-3}$.

The present work includes the improvement of mechanical properties and energy absorption efficiency of cellular TRIP-MC using a new composition based on a more finegrained steel powder and identical zirconia powder. The buckling behavior of the honeycomb channel structure and the internal microstructure evolution within the cell walls after compression will be described in detail as in the papers published previously $[18,19]$.

\section{Experimental Procedure}

In order to fabricate elongated products with various crosssectional shapes the ceramic extrusion technique offers high potential for industrial application.

A previous research has successfully implemented the powder metallurgical method of ceramic extrusion to realize cellular honeycomb specimens with linear channel arrangement [20].
The processing route started with preparing the plastic feedstock by directly batching and mixing the raw materials including plasticizers and water in a conventional single sigma-baking mixer. The desired square-cell macrostructure of the material was achieved by plastic molding in a piston extruder under a pressure ranging from 10 to $11 \mathrm{MPa}$ at room temperature. The cellular extrudates exhibited a crosssectional area of $25.5 \times 25.5 \mathrm{~mm}^{2}$ with in-plane array of 196 channels (196 cpsi-channels per square inch) and a wall thickness of nearly $250 \mu \mathrm{m}$. After the shape fabrication step, square samples $\left(25.5 \times 25.5 \times 25.5 \mathrm{~mm}^{3}\right)$ were cut and dried in an air circulated dryer for $12 \mathrm{~h}\left(40^{\circ} \mathrm{C}\right.$ for $6 \mathrm{~h}$, humidity $80 \%$, followed by $90^{\circ} \mathrm{C}$ for $6 \mathrm{~h}$, humidity $5 \%$ ). The debindering process was carried out at $350^{\circ} \mathrm{C}$ for $90 \mathrm{~m}$ in air atmosphere. Before sintering at $1,350^{\circ} \mathrm{C}$ for $2 \mathrm{~h}$ in an electrical tube furnace with $\mathrm{MoSi}_{2}$ heating elements and $99.9 \%$ Argon atmosphere, the binder-free samples were placed in an alumina crucible and protected against $\mathrm{O}_{2}$ contamination by a Ti-gasketing [18].

Nearly net-shaped honeycomb structures with Mg-PSZ contents of $0,2.5,5$, and 10 vol.\% (denoted as $0 \mathrm{Z}, 2.5 \mathrm{Z}$, etc.) were produced. It has to be noted that the conditions $5 \mathrm{Z}$ and $10 \mathrm{Z}$ were based on AISI 304 steel powder with a median particle size $d_{50}$ of about $45 \mu \mathrm{m}$, whereas the series $0 \mathrm{Z}$ and $2.5 \mathrm{Z}$ were prepared with a more fine-grained steel powder $\left(\mathrm{d}_{50} \approx 27 \mu \mathrm{m}\right)$. Although the binder system (incl. dispersant, tenside, plasticizer, etc.) and the zirconia powder were identical to the precursor materials, described in $[18,19]$, the conditions $0 \mathrm{Z}$ and $2.5 \mathrm{Z}$ appeared to exhibit a stiffer channel network with clearly linear contours than the materials of the previous investigations after final sintering step.

Compression tests of the sintered samples in the outof-plane direction, that is, normal to the cross-sectional honeycomb plane (cf. $X_{3}$-loading direction in Figures 3 and 4), were carried out at a $500 \mathrm{kN}$ servohydraulic universal testing machine type MTS 880 with a displacement rate of $0.016 \mathrm{~mm} \mathrm{~s}^{-1}$ (viz., $8-9 \times 10^{-4} \mathrm{~s}^{-1}$ ) in order to detect the influence of zirconia reinforcement on the stress-strain behavior. The specific energy dissipation in the form of plastic deformation was determined by calculating the area under the load-displacement curves up to accurately defined deformation degrees, normalized to mass or volume of the composite sample (denoted as specific energy absorption SEA) [21]. Representing the mechanical response of each material condition, the test series included three cubed specimens with different composition.

\section{Results and Discussion}

Before testing, all samples were characterized in terms of average linear shrinkage and open porosity (see Table 1) applying multiple runs of density measurements according to Archimedes principle. Due to the different shrinkage behavior during sintering, the obtained overall densities of the honeycomb structures differ between 2.7 and $3.0 \mathrm{~g} \mathrm{~cm}^{-3}$.

The microstructure of an as-received extrudate is shown in Figure 1. After wet etching with the acid solution Beraha 
TABLE 1: Average shrinkages and open porosities of sintered honeycomb specimens.

\begin{tabular}{|c|c|c|}
\hline \multirow{2}{*}{$\begin{array}{l}\text { Fraction of Mg-PSZ } \\
\text { (vol.\%) }\end{array}$} & Shrinkage (\%) & Open porosity (\%) \\
\hline & \multicolumn{2}{|c|}{ After sintering at $1,350^{\circ} \mathrm{C} / 2 \mathrm{~h}$} \\
\hline 0 & 10.1 & 10.3 \\
\hline 2.5 & 11.8 & 7.2 \\
\hline 5 & 13.8 & 8.1 \\
\hline 10 & 14.6 & 7.4 \\
\hline
\end{tabular}

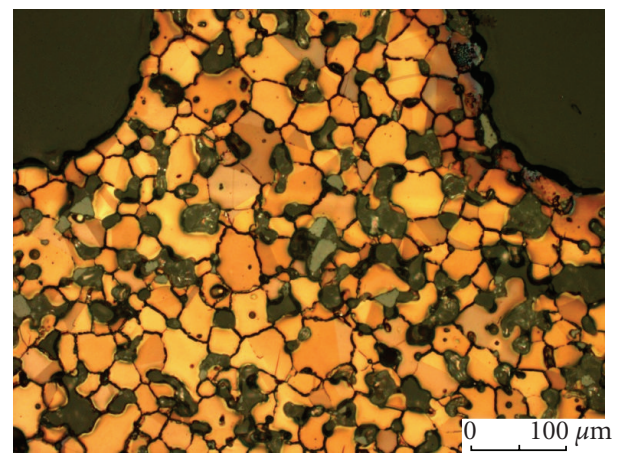

Figure 1: Microstructure inside a cell node of sintered initial state with 2.5 vol.\% Mg-PSZ; Beraha II color etching, zirconia particles (grey) and pores (black) embedded in an austenite matrix (bright yellow up to brown).

II $\left(50 \mathrm{ml} \mathrm{H} \mathrm{H}_{2} \mathrm{O}-\mathrm{HCl}-\left(\mathrm{NH}_{4}\right) \mathrm{HF}_{2}\right.$ as stock solution and $0.5 \mathrm{~g}$ $\mathrm{K}_{2} \mathrm{~S}_{2} \mathrm{O}_{5}$ ), the steel grains are brown-colored exhibiting annealing twins. The zirconia particles show an inhomogeneous distribution with a tendency to the formation of clusters at the triple points of initial steel particles. The relatively low sintering temperature of $1,350^{\circ} \mathrm{C}$ did not allow the zirconia particles to sinter to a close-packed assembly, thus some polyhedral pores are visible.

Figure 2 presents the true compression stress versus plastic compressive strain curves of the four material conditions, starting at $0.2 \%$ offset of the yield strength. The measured differences in the true stress-strain curves will be explained with regard to structural behavior and microstructure changes.

As it is known from previous studies [18, 19], compressive stress at yield rises with increasing volume content of zirconia. The yield stress value of specimen with 10 vol.\% zirconia is about $45 \%$ higher than the pure TRIP-steel specimen (cf. Figure 2). The conditions with a Mg-PSZ content of 0 and 2.5 vol.\% show similar strain hardening behavior, considering that the relatively small zirconia reinforcement results only in slightly higher compression stress values. The maximum compression stress of total test series was sustained by the samples according to condition $2.5 \mathrm{Z}$. In contrast, the specimens reinforced by 5 and 10 vol.\% zirconia exhibit a lower strain hardening. As already mentioned in previous chapter, design and stiffness of these prototype materials appeared to be not well comparable to the conditions $0 \mathrm{Z}$ and $2.5 \mathrm{Z}$ based on fine-grained austenite steel powder. As a consequence of this imperfection, the structure

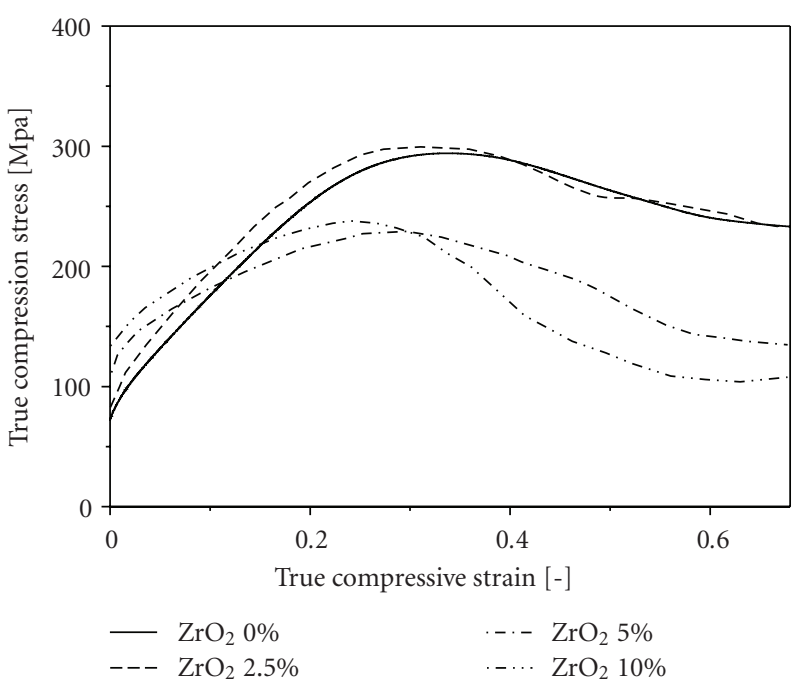

FIgURE 2: True compression stress as a function of plastic compressive strain of the TRIP-steel/Mg-PSZ honeycomb samples with respect to different zirconia fractions.

was unable to sustain higher compression stresses. Moreover, the measured decrease in compression stresses especially at higher deformation degrees can be additionally explained by the rearrangement of zirconia particles in elongated clusters, crack formation on the interface regions of ceramic clusters and the steel matrix, or at residual pores remained after the sintering process. These microstructure phenomena are also demonstrated in the specimen reinforced with 2.5 vol.\% zirconia (see Figures 3(a) and 3(b)).

In summary, honeycomb samples with Mg-PSZ contents of 5 and 10 vol. $\%$ offer a higher strength level than the zirconia-free sample just up to about $10 \%$ and $13 \%$ compressive strain, respectively. After passing the maximum true compression stress of about $235 \pm 5 \mathrm{MPa}$, the stress is reduced because of intense material damage.

The condition with Mg-PSZ fraction of 2.5 vol.\% achieved the highest specific energy absorption with a value of approximately $170 \mathrm{MJ} / \mathrm{m}^{3}$ at $50 \%$ engineering strain. Regarding lower deformation degrees, the composite materials with higher zirconia fractions absorbed more energy than the unreinforced TRIP-steel, due to its higher yield stresses. Typically, SEA values are presented for $20 \%$ and $50 \%$ engineering strain, for example, before the densification within cellular material occurred; see Table 2.

The deformation and collapse behavior of the twodimensional channel structure can be described as follows. After exceeding the offset yield strength the cell walls in the middle of the sample are subject to plastic buckling and shear crushing mechanisms. Our investigations on samples compressed up to high strain values, approximately $60 \%$, revealed a high density of deformation zones (see Figure $4(\mathrm{~b})$ ). The highest strain concentration and martensite formation were noticed in the honeycomb core. Magnetic balance measurements of these crushed sections revealed a ferromagnetic phase content of about 60 vol.\%. The cell walls toward the lateral edges of sample, including the outer skin, deform 


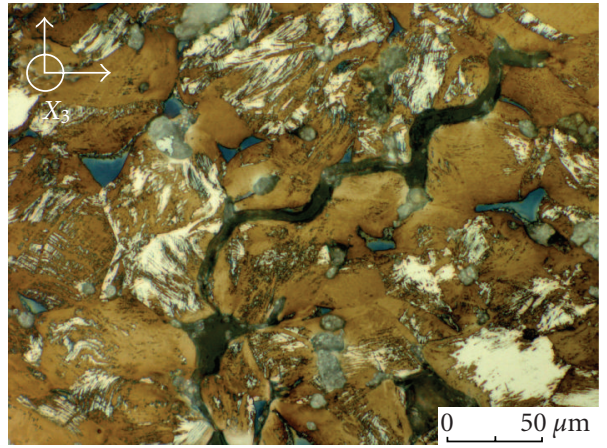

(a)

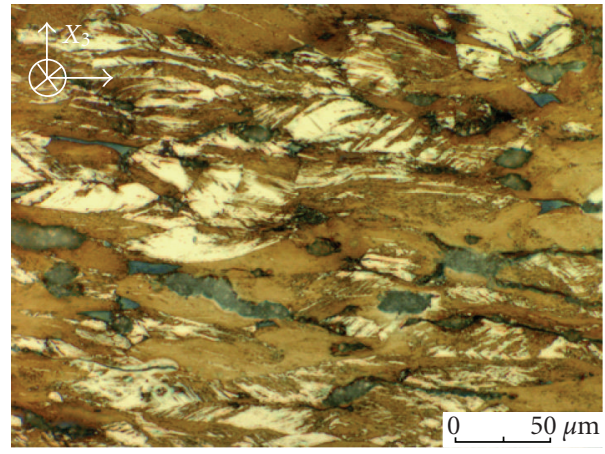

(b)

FIGURE 3: Microstructure of the TRIP-steel/Mg-PSZ honeycomb specimen $2.5 \mathrm{Z}$ after approximately $60 \%$ engineering strain, in view of (a) cross-section with crack in the center and (b) longitudinal section (denoted by $X_{3}$-loading direction in left upper corner).

TABle 2: Specific energy absorption (SEA) of the honeycomb samples at $20 \%$ and $50 \%$ compression strain.

\begin{tabular}{lccc}
\hline Sample & Strain $(\%)$ & SEA $\left(\mathrm{kJ} \mathrm{kg}^{-1}\right)$ & SEA $\left(\mathrm{MJ} \mathrm{m}^{-3}\right)$ \\
\hline $0 \mathrm{Z}$ & 20 & 13.4 & 39.7 \\
$2.5 \mathrm{Z}$ & 20 & 14.3 & 43.1 \\
$5 \mathrm{Z}$ & 20 & 14.1 & 37.5 \\
$10 \mathrm{Z}$ & 20 & 15.0 & 40.4 \\
$0 \mathrm{Z}$ & 50 & 55.8 & 165.5 \\
$2.5 \mathrm{Z}$ & 50 & 56.3 & 169.9 \\
$5 \mathrm{Z}$ & 50 & 47.3 & 125.7 \\
$10 \mathrm{Z}$ & 50 & 43.2 & 116.7 \\
\hline $0 Z^{*}$ & 20 & 12.1 & 32.2 \\
$0 Z^{*}$ & 50 & 53.1 & 143.1 \\
\hline
\end{tabular}

${ }^{*}$ Pure TRIP-steel condition tested by Biermann et al. [19], based on coarse steel powder $\left(\mathrm{d}_{50} \approx 45 \mu \mathrm{m}\right)$.

basically by bending and little extension across their total geometry. Therefore, the studied honeycomb prototype exhibits global buckling of its total structure (see Figure 4(a)) and successive failure of selected walls (cf. Figure 4(b)) but no progressive buckling in terms of multiple folds, as predicted by McFarland [22] and Wierzbicki [23] for similar honeycomb materials. The manufacturing of a relatively close-packed cellular design with high wall thickness $t$ and a high ratio of wall thickness $t$ to cell length $l(t / l)$ results in the prevention of the folding mechanism in the presented square-celled structures. Furthermore, the height-to-width ratio of the test specimen can also have an effect, as proven for cylindrical tubes under quasistatic loading by Andrews et al. [24]. In our study, the strain hardening behavior of the austenite TRIP-steel matrix (as observed by Jing et al. [25]) and the rearrangement of zirconia particles in elongated clusters during deformation influence the nature of the plastic collapse in these composite materials, too.

The optical images, presented in Figure 3, are taken from the largely deformed central region of the cross-section (Figure 3(a)) and the longitudinal section (Figure 3(b)) of the sample $2.5 \mathrm{Z}$. Due to the localized deformation in the cell walls and the agglomeration of zirconia particles, inhomo- geneous slip band formation and martensite transformation were observed. Both micrographs indicate regions of highly deformed austenite grains (uncolored) containing a network of close-packed slip bands and martensite lenses as well as extremely distorted grains which are completely transformed to compact plates of bcc martensite (cf. brown-colored regions in Figure 3). It could be noted that intense martensite formation occurred predominantly in the immediate vicinity of delta ferrite, situated on grain boundaries (indentified as blue-colored particles in Figure 3) and at elongated zirconia clusters (see Figure 3(b)). Additionally, martensite transformation can also appear near cracks as consequence of high local stress concentrations during compressive deformation (Figure 3(a)).

Investigations on microstructure using SEM in combination with EBSD revealed nontransformed regions of austenite and also several slip bands containing bcc martensite. In Figure 5, the austenite is shown in grey color, pores and high angle grain boundaries are shown in black color, and bcc martensite is shown in blue. Magnetic balance examination after interrupted compression tests on zirconia-free samples revealed that the ferromagnetic phase content increased gradually with respect to low deformation degrees. However, above approximately $25 \%$ compressive strain a steep rise of the bcc martensite phase fraction was measured.

For the first time, a composite honeycomb structure was created offering superior ductility and high energy absorption not only up to low strains but also up to high compression degrees. Consistent with the total series of experiments the specimens, containing as little as 2.5 vol.\% zirconia, already revealed a small strengthening effect due to particle reinforcement. Furthermore, the present TRIP-MC condition $2.5 \mathrm{Z}$ provides an increase of energy absorption per unit volume of approximately $19 \%$ compared to the zirconiafree condition produced on basis of the coarse TRIP-steel powder feedstock (listed in the lower part of Table 2), mentioned in [19]. In order to substantiate the effect of particle reinforcement with respect to the compressive flow behavior of these honeycomb structures, it is necessary to carry out a larger test series based on different reproducible material compositions ensuring identical process parameters and raw materials. 


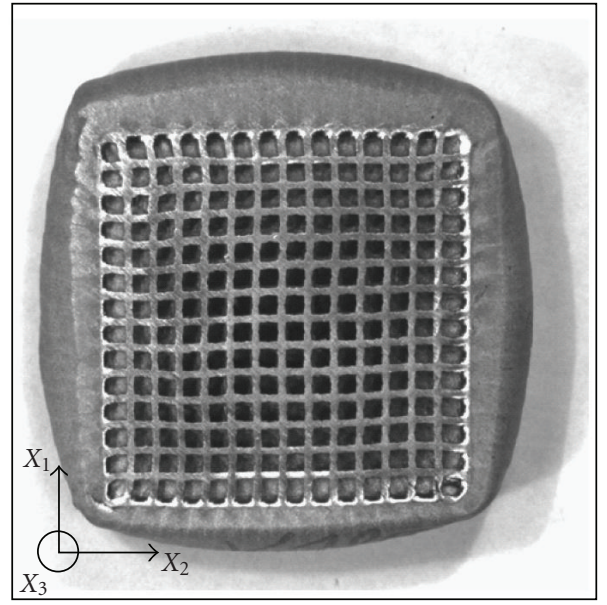

(a)

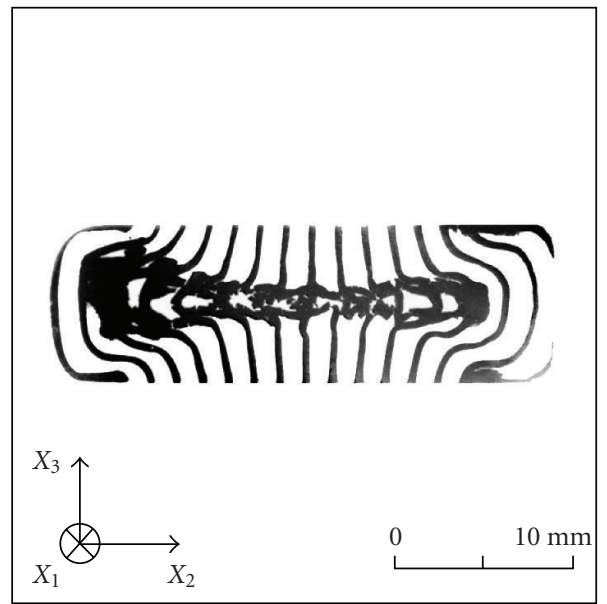

(b)

FIGURE 4: Macrostructure of the TRIP-MC honeycomb specimen with 2.5 vol.\% zirconia after approximately $60 \%$ compressive strain, (a) top view, (b) cross-section after preparation ( $X_{3}$-axis indicates out-of-plane loading).
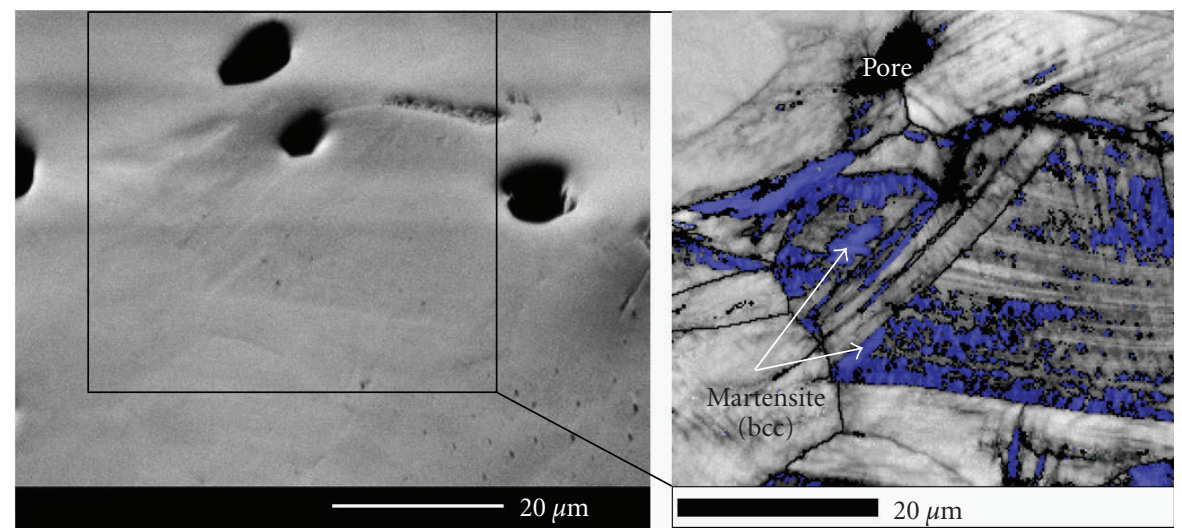

Figure 5: SEM image and EBSD mapping of a zirconia-free ( $0 \mathrm{Z})$ honeycomb sample after quasistatic compression up to $10 \%$ engineering strain (austenite with slip bands: grey shaded, bcc martensite: blue, high angle grain boundaries, and pores: black).

\section{Conclusions}

The powder metallurgical route of ceramic extrusion has been applied to realize a filigree honeycomb design based on austenite stainless TRIP-steel and TRIP-steel/zirconia composite (TRIP-MC) materials. The main results and advancement of the present research are the following.

(i) The square-celled honeycomb structures fabricated by the plastic molding technique show high ductility under compressive loads in the out-of-plane direction. The composite specimens with zirconia content of 5 and 10 vol.\% sustained a maximum compression stress at a strain level up to 10 and $13 \%$, respectively. By the use of fine-grained steel powder and changed composition based on 2.5 vol.\% Mg-PSZ a slight increase in compression strength, but a linear strain hardening, similar to that of the unreinforced condition, could be realized. Furthermore, this cellular composite structure was not subject to a significant strength decrease associated to local material damage.

(ii) The specimen with a zirconia fraction of 2.5 vol.\% revealed the highest specific energy absorption. In this study, the investigated cellular TRIPsteel/zirconia composite material based on 2.5 vol. $\%$ Mg-PSZ achieved a specific energy absorption of $56 \mathrm{~kJ} \mathrm{~kg}^{-1}$ and $170 \mathrm{MJ} \mathrm{m}^{-3}$, respectively.

(iii) Consistently, all samples studied in this topic show extensive formation of strain-induced martensite.

\section{Acknowledgments}

The authors would like to thank the German Science Foundation (DFG) for supporting the scientific work in terms of the Collaborative Research Centre TRIP-Matrix Composites (SFB 799). The authors also acknowledge the support of Dr.-Ing. W. Schärfl and Dipl.-Ing. (FH) K. Zuber in experimental work. 


\section{References}

[1] L. J. Gibson and M. F. Ashby, Cellular Solids-Structure \& Properties, Cambridge University Press, Cambridge, UK, 1997.

[2] A. G. Mamalis, M. Robinson, D. E. Manolakos, G. A. Demosthenous, M. B. Ioannidis, and J. Carruthers, "Crashworthy capability of composite material structures," Composite Structures, vol. 37, no. 2, pp. 109-134, 1997.

[3] M. Pein, V. Laukart, D. G. Feldmann et al., "Concepts for energy absorbing support structures and appropriate materials," in Proceedings of the 22nd International Congress of Aeronautical Sciences, Hamburg, Germany, 2006.

[4] M. Kiser, M. Y. He, and F. W. Zok, "Mechanical response of ceramic microballoon reinforced aluminum matrix composites under compressive loading," Acta Materialia, vol. 47, no. 9, pp. 2685-2694, 1999.

[5] F. Simančík, "Metallic foams—ultra light materials for structural applications," Inzynieria, Materialowa, vol. 47, pp. 2685 2694, 1999.

[6] H. Zhao, I. Elnasri, and S. Abdennadher, "An experimental study on the behaviour under impact loading of metallic cellular materials," International Journal of Mechanical Sciences, vol. 47, no. 4-5, pp. 757-774, 2005.

[7] A. Rabiei, L. Vendra, N. Reese et al., "Processing and characterisation of a new composite metal foam," in Proceedings of the 4th International Conference on Porous Metals and Metal Foaming Technology (MetFoam '05), pp. 369-374, Kyoto, Japan, 2005.

[8] B. P. Neville and A. Rabiei, "Composite metal foams processed through powder metallurgy," Materials and Design, vol. 29, no. 2, pp. 388-396, 2008.

[9] C. Park and S. R. Nutt, "PM synthesis and properties of steel foams," Materials Science and Engineering A, vol. 288, no. 1, pp. 111-118, 2000.

[10] J. Pflug, B. Vangrimde, I. Verpoest, P. Bratfisch, and D. Vandepitte, "Continuously produced honeycomb cores," in Proceedings of the International SAMPE Symposium and Exhibition, vol. 48, pp. 602-611, May 2003.

[11] H. N. G. Wadley, "Multifunctional periodic cellular metals," Philosophical Transactions of the Royal Society A, vol. 364, no. 1838, pp. 31-68, 2006.

[12] F. Côté, V. S. Deshpande, N. A. Fleck, and A. G. Evans, “The compressive and shear responses of corrugated and diamond lattice materials," International Journal of Solids and Structures, vol. 43, no. 20, pp. 6220-6242, 2006.

[13] F. Côté, V. S. Deshpande, N. A. Fleck, and A. G. Evans, "The out-of-plane compressive behavior of metallic honeycombs," Materials Science and Engineering A, vol. 380, no. 1, pp. 272280, 2004.

[14] D. D. Radford, G. J. McShane, V. S. Deshpande, and N. A. Fleck, "Dynamic compressive response of stainless-steel square honeycombs," Journal of Applied Mechanics, Transactions ASME, vol. 74, no. 4, pp. 658-667, 2007.

[15] W. E. Baker, T. C. Togami, and J. C. Weydert, "Static and dynamic properties of high-density metal honeycombs," International Journal of Impact Engineering, vol. 21, no. 3, pp. 149-163, 1998.

[16] Y. Guo, Y. Zhou, D. Li, X. Duan, and T. Lei, "Microstructure and performance of 2Y-PSZ/TRIP steel composites," Journal of Materials Science and Technology, vol. 19, no. 2, pp. 137-140, 2003.
[17] Y. Zhou, Y.-K. Guo, D.-B. Li, and X.-M. Duan, "Effects of load mode on mechanical properties of $\mathrm{ZrO}_{2}(2 \mathrm{Y}) / \mathrm{TRIP}$ steel composites," Transactions of Nonferrous Metals Society of China, vol. 13, no. 5, pp. 1086-1091, 2003.

[18] C. G. Aneziris, W. Schärfl, H. Biermann, and U. Martin, "Energy-absorbing TRIP-Steel/Mg-PSZ composite honeycomb structures based on ceramic extrusion at room temperature," International Journal of Applied Ceramic Technology, vol. 6, no. 6, pp. 727-735, 2009.

[19] H. Biermann, U. Martin, C. G. Aneziris et al., "Microstructure and compression strength of novel TRIP-steel/Mg-PSZ composites," Advanced Engineering Materials, vol. 11, no. 12, pp. 1000-1006, 2009.

[20] C. G. Aneziris, W. Schärfl, and B. Ullrich, "Microstructure evaluation of $\mathrm{Al}_{2} \mathrm{O}_{2}$ ceramics with $\mathrm{Mg}$-PSZ- and $\mathrm{TiO}_{2}$ additions," Journal of the European Ceramic Society, vol. 27, no. 10, pp. 3191-3199, 2007.

[21] G. C. Jacob, J. F. Fellers, S. Simunovic, and J. M. Starbuck, "Energy absorption in polymer composites for automotive crashworthiness," Journal of Composite Materials, vol. 36, no. 7, pp. 813-850, 2002.

[22] R. K. McFarland, "Hexagonal cell structures under postbuckling axial load," AIAA Journal, vol. 1, no. 6, pp. 1380$1385,1963$.

[23] T. Wierzbicki, "Crushing analysis of metal honeycombs," International Journal of Impact Engineering, vol. 1, no. 2, pp. 157-174, 1983.

[24] K. R. F. Andrews, G. L. England, and E. Ghani, "Classification of the axial collapse of cylindrical tubes under quasi-static loading," International Journal of Mechanical Sciences, vol. 25, no. 9-10, pp. 687-696, 1983.

[25] Y. Jing, S. Guo, J. Han, Y. Zhang, and W. Li, "Fabrication and compressive performance of plain carbon steel honeycomb sandwich panels," Journal of University of Science and Technology Beijing, vol. 15, no. 3, pp. 255-260, 2008. 

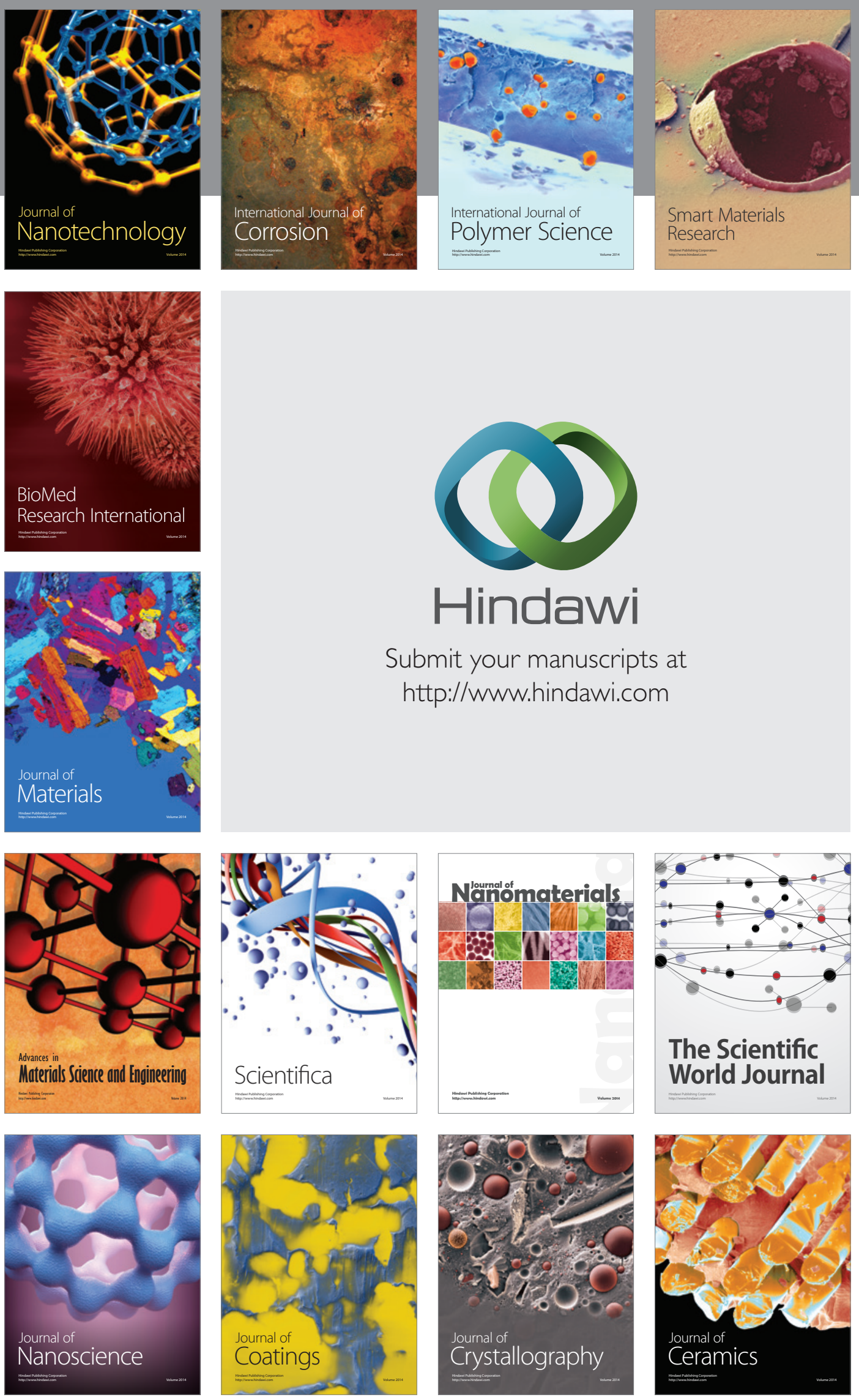

The Scientific World Journal

Submit your manuscripts at

http://www.hindawi.com

\section{World Journal}

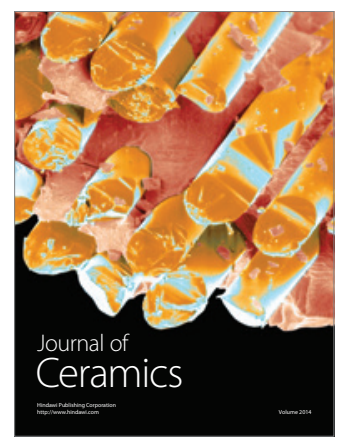

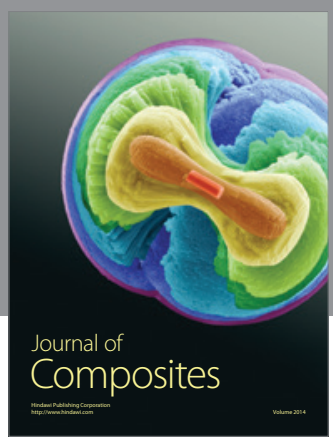
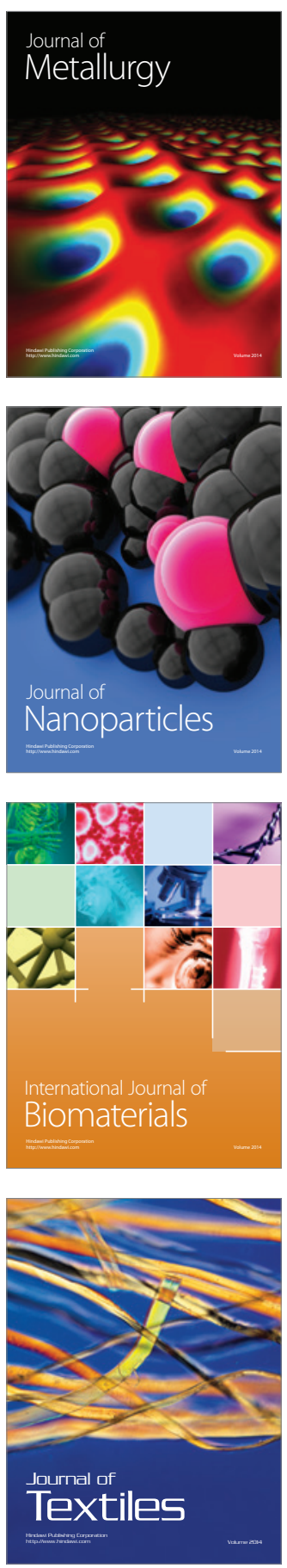